\title{
Significant enhancement of structural stability of the hyperhalophilic ADH from Haloferax volcanii via en- trapment on metal organic framework support
}

\author{
Cristina Carucci ${ }^{1}$, Larah Bruen ${ }^{2}$, Victoria Gascón ${ }^{1}$, Francesca Paradisi, ${ }^{2,3}$ Edmond Magner ${ }^{* 1}$ \\ ${ }^{1}$ Department of Chemical Sciences, Bernal Institute, University of Limerick, Limerick, Ireland, \\ ${ }^{2}$ Centre for Synthesis and Chemical Biology, University College Dublin, Dublin, Ireland, \\ ${ }^{3}$ School of Chemistry, University Park Campus, University of Nottingham, UK
}

\begin{abstract}
The use of an in-situ immobilization procedure for the immobilization of hyperhalophilic alcohol dehydrogenase in a metal organic framework material is described. The easy and rapid in situ immobilization process enables retention of activity over a broad range of $\mathrm{pH}$ and temperature together with a decrease in the halophilicity of the enzyme. The catalytic activity of the immobilized enzyme was studied in non-aqueous solvent mixtures with the highest retention of activity in aqueous solutions of methanol and acetonitrile. The approach demonstrates that this immobilization method can be extended to hyperhalophilic enzymes with enhancements in activity and stability.
\end{abstract}

\section{Introduction}

Halophilic enzymes are of interest in biocatalysis due to their resistance to elevated temperatures, high concentrations of salt, and the ability to retain catalytic activity at extreme $\mathrm{pH}$ values and in the presence of organic solvents. ${ }^{1-2}$ These enzymes are of interest in applications such as synthesis, food processing and bioremediation, among others. ${ }^{3}$ Alcohol dehydrogenase (ADH) is used for the production of chiral alcohols that are used as intermediates in pharmaceutical industries. ${ }^{4}$ For example ADH is employed in the preparation of (S)-tert-leucine, an intermediate in the production of the antiviral agent, Atazanavir. ${ }^{5}$ Enzymes such as Halopherax volcanii can possess advantages such as catalytic activity under extreme conditions of temperature and $\mathrm{pH} .{ }^{6}$ In particular Archea

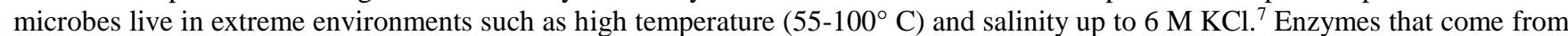
this source are active under the same conditions. The alcohol dehydrogenase from Haloferax volcanii (HvADH2) utilises NADP(H) ( $\beta$ - nicotinamide adenine dinucleotide phosphate) as a co-factor (with some activity with NADH-nicotinamide adenine dinucleotide) ${ }^{8}$ is stable at high temperature over a broad $\mathrm{pH}$ range ${ }^{9}$ and retains some activity in the presence of organic solvents including DMSO, $\mathrm{MeOH}$ and ACN. ${ }^{1}$ However, the operational use of this enzyme in its soluble form can be restricted due to its low stability and difficulties in re-use. ${ }^{10} \mathrm{HvADH} 2$ can undergo rapidly and irreversible denaturation and dissociates in solution at low concentrations of $\mathrm{NaCl}$ or $\mathrm{KCl}$ (below $1 \mathrm{M}$ ). Immobilization of the enzyme can overcome these disadvantages by increasing the reusability of the system, enhancing enzyme and facilitating product separation and biocatalyst recovery. Previous work demonstrated that HvADH2 can be covalently attached to polymeric beads. ${ }^{11} \mathrm{~A}$ wide range of supports can be used for enzyme immobilisation, ${ }^{12}$ including natu$\mathrm{ral}^{13}$ and synthetic ${ }^{14}$ polymers, and inorganic porous materials. ${ }^{15-19}$ The use of metal organic framework materials (MOF) as supports for the immobilization of enzymes has been described recently. ${ }^{20-22} \mathrm{MOF}$ materials have been used for water adsorption ${ }^{23}$ and gas storage ${ }^{24}$, for separation, ${ }^{25}$ sensing, ${ }^{26}$ heterogeneous catalysis, ${ }^{27}$ nanoreactors and drug delivery ${ }^{28}$ among others. ${ }^{29-30}$ The wide range of MOF structures arises from their topological and compositional versatility. ${ }^{20,31}$ While the microporous nature of MOFs makes it difficult to incorporate large macromolecules such as enzymes, recent studies have demonstrated that proteins can be retained within the cavities of some MOFs. ${ }^{32-34}$ A number of reports have focused on developing a general immobilization methodology to encapsulate an enzyme in one simple step. ${ }^{30,35-36}$ Many studies focused on the in-situ encapsulation of enzymes in aqueous system in materials such as zeolite-like structures. ${ }^{37-40}$ Our recent work demonstrated that it is possible to encapsulate a range of enzymes (including alcohol dehydrogenase from Saccharomyces cerevisiae) in a facile manner using a Fe-BTC MOF material that is structurally similar to commercially available Basolite F300. ${ }^{41-44}$ With this approach, unlike other immobilisation methods, enzyme immobilization occurs in situ, at mild $\mathrm{pH}$ and at room temperature in a rapid (10 minutes) and facile manner. In this work, we describe the in-situ immobilization of the halophlic HvADH2 in the Fe-BTC MOF. Enzyme specificity, stability and tolerance to organic solvents were systematically studied. This in-situ immobilization of the enzyme resulted in increased stability over a wider range of pH and temperature with retention of activity in reuse up to 4 cycles. Electrostatic interactions between the halophilic enzyme and the Fe-BTC MOF could explain the enhancement in activity and decreases in halophilicity of the immobilized enzyme. 


\section{Materials and methods}

Ferric chloride $\left(\mathrm{FeCl}_{3} \cdot 6 \mathrm{H}_{2} \mathrm{O}, 97 \%\right)$, sodium hydroxide $(\mathrm{NaOH}>95 \%), \mathrm{KCl}(>99 \%)$, trimesic acid $\left(\mathrm{H}_{3} \mathrm{BTC}>95 \%\right)$, alcohol dehydrogenase from Saccharomyces cerevisiae, ethanol (96\%), $\beta$-nicotinamide adenine dinucleotide sodium salt hydrate NADH and phosphate hydrate $\mathrm{NADP}^{+}(>99 \%)$, acetonitrile (99.8\%), dimethyl sulfoxide ACS ( $\left.\geq 99.9 \%\right)$, methanol anhydrous (99.8\%), tetrahydrofuran (> 99\%), acetic acid, sodium acetate (anhydrous), citric acid, tri-sodium citrate dehydrate, Tris-base and hydrochloric acid were purchased from Sigma-Aldrich. All reagents were used as received without further purification. De-ionised water (18.2 M $\Omega$ $\mathrm{cm})$ was used for all aqueous solutions.

\subsection{HvADH2 expression and purification}

HvADH2 was expressed as reported in Timpson et al., ${ }^{8}$ single colony of Haloferax volcanii containing the pTA1205 vector was inoculated into $5 \mathrm{~mL} \mathrm{Hv}$-YPC media and grown at $45^{\circ} \mathrm{C}$ over $24 \mathrm{~h}$, and used to inoculate $270 \mathrm{~mL} \mathrm{Hv}$-YPC, which was grown a further $24 \mathrm{~h}$. Protein expression was induced by the addition of $5 \mathrm{mM}$ L-tryptophan and the culture shaken overnight. Cells were harvested, lysed by sonication and purified by immobilized metal ion affinity chromatography (IMAC) as reported ${ }^{8}$ using a gradient of EDTA to elute. Pure HvADH2 was stored in $100 \mathrm{mM}$ Tris-HCl, pH 8.0, containing $3 \mathrm{M} \mathrm{KCl}$.

\subsection{Protein concentration determination}

The protein concentration of HvADH2 was analysed by Bradford assay ${ }^{45}$ using a commercially available Bio-Rad protein assay with bovine serum albumin (BSA) as standard.

\subsection{Determination of the activity of the Enzyme@MOF}

The catalytic activities of ADH from Saccharomyces cerevisiae (ScADH) and Haloferax Volcanii (HvADH2) were determined spectrophotometrically by measuring the increase in absorbance due to the production of NADH at $340 \mathrm{~nm} .{ }^{46}$ The activity of HvADH2 and HvADH2@MOF were measured at $50{ }^{\circ} \mathrm{C}$ in Tris- $\mathrm{HCl}$ buffer $(100 \mathrm{mM}, \mathrm{pH} 10)$ and $\mathrm{KCl}(3 \mathrm{M})$ unless stated otherwise. The reaction mixture was analysed in a quartz cuvette and consisted of $0.25 \mathrm{~mL}$ of $\mathrm{NADP}^{+}(1 \mathrm{mM}), 0.01 \mathrm{~mL}$ of ethanol $(50 \mathrm{mM})$, and $1.49 \mathrm{~mL}$ of buffer Tris- $\mathrm{HCl} 100 \mathrm{mM}$ (pH 10, $3 \mathrm{M} \mathrm{KCl}$ ). A $0.1 \mathrm{~mL}$ aliquot of the enzyme solution, supernatant or HvADH2@MOF was then added into the reaction mixture and the progress of the reaction was continuously monitored for 10 minutes by measuring the adsorption at $340 \mathrm{~nm}$. The activity of ADH from S. cerevisiae was measured at $25{ }^{\circ} \mathrm{C}$, in Tris- $\mathrm{HCl}$ buffer $100 \mathrm{mM} \mathrm{pH} 8$ unless stated otherwise. The reaction mixture was analysed in a quartz cuvette and consisted of $0.25 \mathrm{~mL}$ of NAD $(1 \mathrm{mM}), 0.01 \mathrm{~mL}$ of ethanol $(50 \mathrm{mM})$, and $1.49 \mathrm{~mL}$ of buffer Tris- $\mathrm{HCl}(100 \mathrm{mM}, \mathrm{pH}$ 8). A $0.1 \mathrm{~mL}$ aliquot of the enzyme solution, supernatant or ScADH@MOF was then added to the reaction mixture and the reaction was continuously monitored for 10 minutes by measuring the adsorption at $340 \mathrm{~nm}$ and $25^{\circ} \mathrm{C}$. All activity measurements were performed in triplicate and the average value reported.

\subsection{Temperature effect on the activity of HvADH2@MOF}

The activity of HvADH2@MOF was examined over the temperature range from $40{ }^{\circ} \mathrm{C}$ to $80{ }^{\circ} \mathrm{C}$, using thermo-bath and Shimadzu spectrophotometer UV-18000 CE 230 equipped with a temperature controller. 10 mg of HvADH2@ MOF was resuspended in Tris buffer/solution and an aliquot of $0.1 \mathrm{~mL}$ of suspension was used to measure its biocatalyst activity.

\section{5 pH effect on the activity of HvADH2@MOF}

The activity of HvADH2@MOF was examined over the pH range between $2-6$ (100 mM citrate buffer), pH 7 (100 mM phosphate buffer $\mathrm{KCl} 3 \mathrm{M}$ ), and Tris- $\mathrm{HCl}(100 \mathrm{mM} \mathrm{KCl} 3 \mathrm{M})$ for $\mathrm{pH}$ above 7. $10 \mathrm{mg} \mathrm{HvADH} 2 @ \mathrm{MOF}$ was resuspended in the appropriate buffer and an aliquot of $100 \mu \mathrm{L}$ of suspension was used for the enzymatic assay. All activity measurements were performed in triplicate and the average value reported.

\subsection{Ionic strength effect of KCl on the activity of HvADH2@MOF}

The activity of HvADH2@MOF was examined in a range of different $\mathrm{KCl}$ concentration $(0.5 / 1 / 1.5 / 3 / 4 \mathrm{M})$ after 1 and $24 \mathrm{~h}$ in buffer. 10 mg HvADH2@MOF was resuspended in the Tris buffer $100 \mathrm{mM} \mathrm{pH} 10$ at different $\mathrm{KCl}$ concentrations and an aliquot of $100 \mu \mathrm{L}$ of suspension was used for the assay. All activity measurements were performed in triplicate and the average value reported.

\subsection{Organic solvents effect on the activity of HvADH2@MOF}

The activity of HvADH2@MOF was examined in a range of organic solvents. The HvADH2@MOF was resuspended in buffer Tris$\mathrm{HCl}(100 \mathrm{mM} \mathrm{KCl} 3 \mathrm{M}) \mathrm{pH} 10$ with 5\% or 10\% of organic solvent. The HvADH2@MOF was stored with the buffer/solvent mixture, keeping under stirring and the activity was measured after 24 and 48 hours at room temperature.

\subsection{In-situ immobilization of HvADH2 in metal organic frameworks}

The support material was reported previously ${ }^{41,43,47}$ and prepared as follows: Solution 1 was prepared by dissolving $0.263 \mathrm{~g}$ of trimesic acid $\left(\mathrm{H}_{3} \mathrm{BTC}\right)$ in $3.685 \mathrm{~mL}$ of $\mathrm{NaOH} 1.06 \mathrm{M}$ of $\mathrm{pH}=8$; solution 2 was made up by dissolving the appropriate amount of enzyme in $6.388 \mathrm{~mL}$ of deionized water: solution 3 of $\mathrm{pH}=2$ was prepared by dissolving $0.508 \mathrm{~g}$ of $\mathrm{FeCl}_{3} \cdot 6 \mathrm{H}_{2} \mathrm{O}$ in $10 \mathrm{~g}$ of $\mathrm{H}_{2} \mathrm{O}$. 
Solution 2 was added to solution 1, while the $\mathrm{pH}$ of the mixture was monitored ( $\mathrm{pH}$ remained at ca. 7.0). Solution 3 was then added dropwise into the mixture under gentle magnetic stirring. This procedure resulted in the immediate appearance of a reddish brown solid. The resultant suspension was maintained under stirring at room temperature $\left(25^{\circ} \mathrm{C}\right)$ for 10 minutes. The obtained solid was recovered by vacuum filtration and washed with deionised water, and dried at room temperature. Measurements on the effect of temperature, $\mathrm{pH}$, ionic strength and organic solvents were all performed post synthesis, after the formation of the MOF.

\subsection{Instrumentation}

Scanning electron microscopy (SEM) studies were carried out using a HITACHI SU-70. Samples were coated with gold prior the analysis. $\mathrm{pH}$ values were measured using a Thermo Scientific Orion 2-star benchtop $\mathrm{pH}$ meter. A Shimadzu spectrophotometer UV18000 CE 230 equipped with a temperature controller was used for activity tests. Dynamic light scattering (DLS) was performed using a Zetasizer Malvern Nano ZSP by dilution (20x) of each sample suspension in de-ionised water.

\section{Results and discussion}

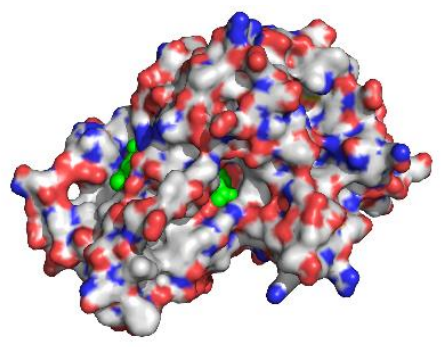

Figure 1. Model of surface residues of HvADH2, with positively charged (blue) and negatively charged side chains (red). The NADP ${ }^{+}$ cofactor (green) is buried in the enzyme cleft.

As a halophilic enzyme, the activity and stability of HvADH2 is strongly affected by the concentration of salt, with concentrations of $>3 \mathrm{M} \mathrm{KCl}$ are normally required for detecting catalytic activity. Halophilic enzymes usually possess more acidic residues on the surface that are stabilized by the presence of high concentrations of $\mathrm{K}^{+}{ }^{6}$ Halophilic enzymes possess less hydrophobic amino acids than other enzymes. They are stable at high salt concentrations, a stability that can arise from increased hydrophobic forces resulting from high concentrations of $\mathrm{K}^{+}{ }^{48}$ The stability of $\mathrm{HvADH} 2$ is extremely sensitive to the electrostatic interactions between the amino acid residues and $\mathrm{K}^{+}$. In the absence of salt, the tertiary structure of the enzyme is destabilize, resulting in denaturation. ${ }^{49}$
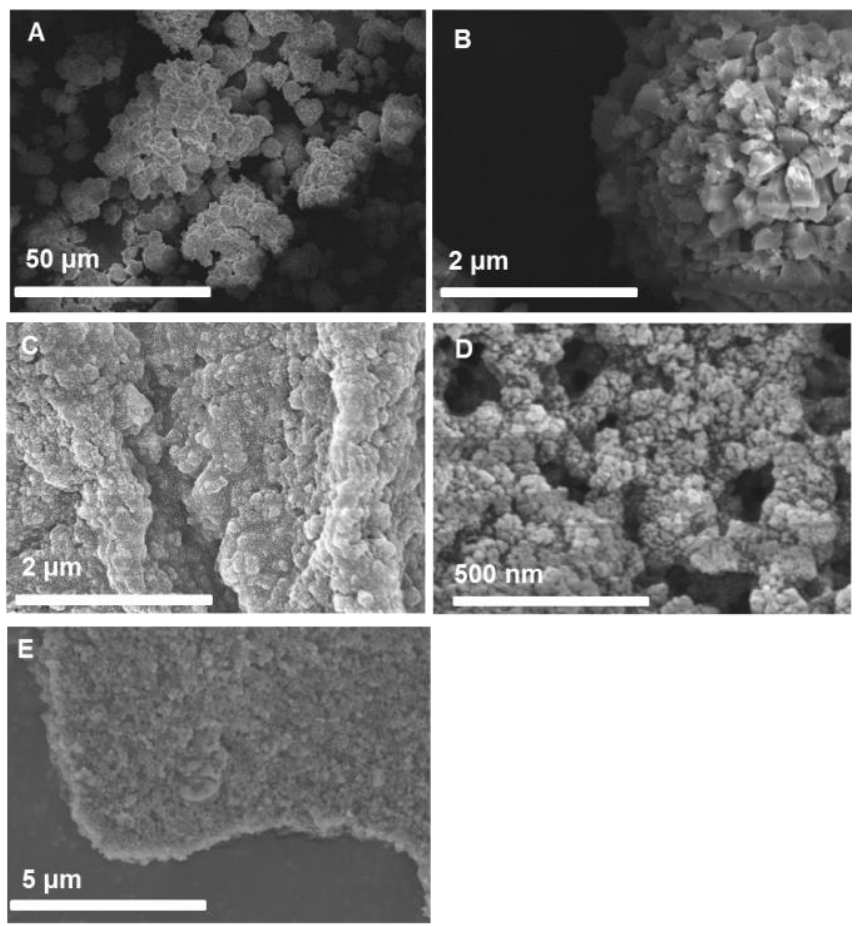

Figure 2. SEM images of HvADH2@MOF (A, B), ScADH@MOF (C, D) and of FE-BTC MOF (E). 
ScADH@MOF (Sc-Saccharomyces cerevisiae) samples were prepared and characterized for comparison purposes. Scanning electron microscopy images of the ScADH@MOF (Figure 2 C-D) show the presence of uneven agglomerates of particles, in agreement with a previous study. ${ }^{41}$ The MOF itself possesses a homogenous particle size and morphology (Figure 2 E). The shape of HvADH2@MOF particles differs from ScADH@MOF. HvADH2@MOF is comprised of semi-cubical sharp particles joined together in neat agglomerates. In comparison with MOF and with ScADH@MOF, the particle size of HvADH2@MOF was significantly larger. DLS measurements show a mean particle size of 150,500 and $550 \mathrm{~nm}$ for MOF, ScADH@MOF and HvADH2@MOF, respectively (Figure S1) ${ }^{41}$ It has been previously reported that glucose oxidase and lipase encapsulated in MOF show a particle size of 479 and $483 \mathrm{~nm}$ respectively. ${ }^{41}$ This change in particle size follows the enzymes size (GOx $\approx 5 \times 7 \times 9 \mathrm{~nm}$, LIP $\approx 3 \times 4 \times 5 \mathrm{~nm}, \mathrm{ADH} \approx 6 \times 7 \times 11$ $\mathrm{nm}$ ). " SEM (Figure 2) and DLS measurements (Figure SI 1) showed that in comparison to MOF, no significant changes in the structure of HvADH2@MOF were observed. The differences in shape and particle dimensions depend on the enzyme encapsulated in the material and is indicative of the successful encapsulation of the enzyme in the MOF. All of the enzyme in entrapped in the MOF. Confocal measurements demonstrate that, when performing the immobilization on MOF in-situ, the enzyme is present and encapsulated within the material. BET measurements of $\mathrm{MOF}^{41}$ showed a pore volume of $0.57 \mathrm{~cm}^{3} / \mathrm{g}$ and a total surface area of 753 $\mathrm{m}^{2} / \mathrm{g}$ area which decreased to $0.15 \mathrm{~cm}^{3} / \mathrm{g}$ and $32 \mathrm{~m}^{2} / \mathrm{g}$, respectively, in the presence of ADH, indicating suggests that the enzyme is encapsulated within the mesopores of the material.

\subsection{Thermal stability}

For comparison purposes, the activity of ADH (S. cerevisiae) was examined and displayed a maximum activity at $25{ }^{\circ} \mathrm{C}$ with a specific activity of $22.7 \pm 1.4 \mathrm{U} / \mathrm{mg}$. At $50{ }^{\circ} \mathrm{C}$, the enzyme retained approximately $0.4 \%$ of its activity $(0.1 \pm 0.4 \mathrm{U} / \mathrm{mg})$ demonstrating that the enzyme is not able to function properly at temperatures higher than $25^{\circ} \mathrm{C}$. In solution $\mathrm{ADH}$ S. cerevisiae showed almost no activity at $50^{\circ} \mathrm{C}$, the MOF immobilised enzyme was active $(0.34 \mathrm{U} / \mathrm{mg})$. In comparison, $\mathrm{HvADH} 2$ showed a peak activity at $90^{\circ} \mathrm{C}^{8}$ however, this temperature was not used due to the difficult assay conditions i.e. evaporation of the analyzed solution. On examination of the activity of $\mathrm{HvADH} 2$ and $\mathrm{HvADH} 2 @ \mathrm{MOF}$ as a function of temperature (Figure 3) the optimal activity for the HvADH2@MOF occurred at a temperature $10^{\circ} \mathrm{C}$ higher than $\mathrm{HvADH} 2\left(50^{\circ} \mathrm{C}\right.$ versus $\left.60^{\circ} \mathrm{C}\right)$. In this range $\mathrm{HvADH} 2$ and HvADH2@ MOF present the same trend with a decrease in activity of $75 \%$ from $60{ }^{\circ} \mathrm{C}$ to $80{ }^{\circ} \mathrm{C}$ for $\mathrm{HvADH}$ and $71.5 \%$ for HvADH2@MOF. At $60^{\circ} \mathrm{C}$ $\mathrm{HvADH} 2 @ \mathrm{MOF}(0.30 \pm 0.06 \mathrm{U} / \mathrm{mg})$ had significantly higher activity than the free enzyme $(0.08 \pm 0.02 \mathrm{U} / \mathrm{mg})$.

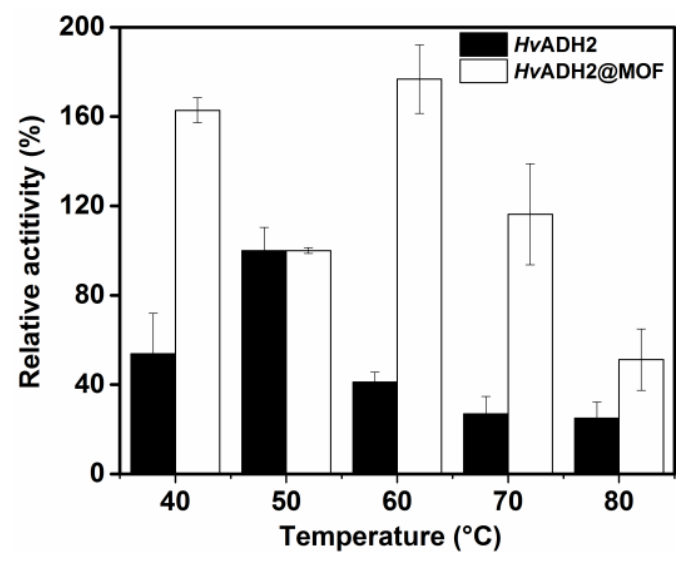

Figure 3. Plot of the activity of HvADH2@MOF and HvADH2 as a function of temperature. The activity was normalized at $50{ }^{\circ} \mathrm{C}$ for $\mathrm{HvADH} 2(0.19 \pm 0.02 \mathrm{U} / \mathrm{mg})$ and HvADH2@MOF $(0.157 \pm 0.002$ $\mathrm{U} / \mathrm{mg})$. Note: the activity of $\mathrm{HvADH} 2 @ \mathrm{MOF}$ exceeds $100 \%$ because its maximum activity occurs at $60^{\circ} \mathrm{C}(0.28 \mathrm{U} / \mathrm{mg} \pm 0.06)$

\section{$3.2 \mathrm{pH}$ activity profile}

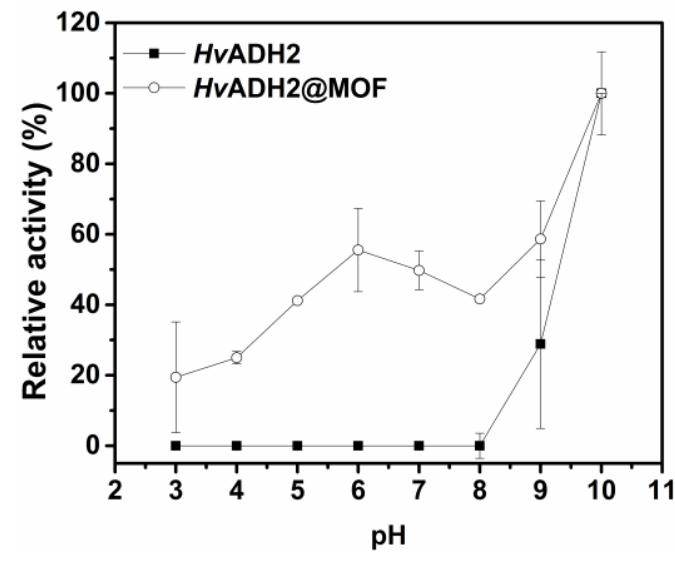

Figure 4. Plot of the specific activity of HvADH2@MOF(o) and $\mathrm{HvADH} 2(\mathbf{a})$ as function of $\mathrm{pH}$. The activity was normalized at $\mathrm{pH} 10$ for $\mathrm{HvADH} 2(0.66 \pm 0.03 \mathrm{U} / \mathrm{mg})$ and for HvADH2 @MOF $(1.32 \pm 0.15$ $\mathrm{U} / \mathrm{mg}$ ).

$\mathrm{HvADH} 2$ in free form and immobilized displayed optimal activity at $\mathrm{pH}$ 10 (Figure 4) in agreement with recent studies on the same enzyme. ${ }^{50}$ The activity of $\mathrm{HvADH} 2$ at different $\mathrm{pH}$ values was also examined in the presence of various solvents. ${ }^{11}$ As expected HvADH2 shows a decrease in activity in by decreasing the salt concentration. Surprisingly in the presence of DMSO 5\% the optimal concentration of salt requirement for $\mathrm{HvADH} 2$ decrease from $3 \mathrm{M} \mathrm{KCl}$ to $2 \mathrm{M} \mathrm{KCl}$. Moreover at $\mathrm{pH} 6$ free HvADH2 shows almost no activity but it shows up to $40 \%$ more activity in the presence of DMSO. ${ }^{1}$ They found an explanation in the stabilizing effect of DMSO on amino acidic residue such as cysteines which are involved in the structure of the active site of this halophilic enzyme. A similar reason could be found in the stabilizing effect of the immobilization 
over all the studied $\mathrm{pH}$ range. Interestingly, while the free form lost its activity at $\mathrm{pH}$ below 8, HvADH2@ MOF retained up to 60\% of its activity at pH 6. In fact specific activity of HvADH2@MOF is higher in all pH range (Figure 4). Even at extremely low pH values as pH 3 HvADH2@MOF shows $0.3 \pm 0.2 \mathrm{U} / \mathrm{mg}$. Halophilic enzymes are usually very inactive at acidic pH indicating that the in-situ immobilization strategy in MOF can be used to immobilize extremo-enzymes. The pH profile of HvADH2@MOF is broader than that of the free HvADH2. HvADH2 displayed no activity at pH 3-8, while HvADH2@MOF was active. This may be due to the stabilizing effect of the MOF on the structure of the enzyme. The encapsulation of glucoamylase in a metal organic framework structure stabilized the conformation of the enzyme ${ }^{51}$ with FT-IR data showing that a significant change in the secondary structure of the enzyme occurring on immobilization. This change also resulted in an increase in catalytic activity. The increased stability of immobilised HvADH2, even at low pH may arise from the same effect in which the MOF not only protects the enzyme from the external environment but promotes the optimal enzyme configuration even under unfavorable conditions.

\subsection{Effect of salt concentration}

Halophilic organisms adapt to high extracellular salt in one of two ways. Halophilic enzymes inhabit environments at extremely high salt concentrations (> 1.5 M). Most haloarchaea accumulate high intracellular potassium and chloride ion concentrations, usually near saturation levels, in order to maintain osmotic balance with their environment. ${ }^{52}$ This "salting in" strategy ensures that the proteins within the cell are capable of functioning at this high salt concentration, and indeed, will likely unfold at low salt concentrations., 53 On the other hand, haloadaptation involves accumulation of organic solutes in the cytoplasm, and exclusion of salt, to maintain osmotic pressure. ${ }^{1}$ This "salting out" strategy is much more widespread than the "salting in" method. The organic solutes do not affect the internal proteins and as such, these proteins do not require salt to function. ${ }^{10}$ Haloferax volcanii, a haloarchaea, utilises the "salting in" strategy and as a result, the proteins within it require high salt concentrations in order to properly fold and function. ${ }^{54-55} \mathrm{HvADH2}$ functions optimally in 3-4 M KCl, and will dissociate from a tetramer to a dimer if incubated in concentrations of $1 \mathrm{M}$ salt or less causing the denaturation of the enzyme. ${ }^{8}$ Those enzymes possess extensive ion pair networks which prevent precipitation in solution and enable catalytic activity at high salt concentrations. Nevertheless, immobilization of $H$. mediterranei aldolase has been reported to reduce the requirement for high salt concentrations. ${ }^{56}$ Since halophilic enzymes have a limited use in industry due to the requirement for high salt concentrations they may become easier to handle when immobilized. For this reason the effect of the salt concentration on the activity of the free and immobilised enzymes was studied in $100 \mathrm{mM}$ Tris- $\mathrm{HCl}$ buffer $\mathrm{pH} 10$ over a range of KCl concentrations $(0,1.5$ and $3 \mathrm{M})$. The salt concentration required to have activity with the immobilised form is lower than that one required for the free form. The immobilization of the soluble enzyme was performed in the presence of $3 \mathrm{M} \mathrm{KCl}$. Even at $0 \mathrm{M} \mathrm{KCl} \mathrm{HvADH2@MOF}$ show $80 \%$ retention of activity that remains constant up to 3-4 $\mathrm{M} \mathrm{KCl}$. On the other hand $\mathrm{HvADH} 2$ presents no activity when no salt is present with an increasing measurable activity just starting from the addition of $0.5 \mathrm{M} \mathrm{KCl}$ and with a maximum at $4 \mathrm{M} \mathrm{KCl}$.

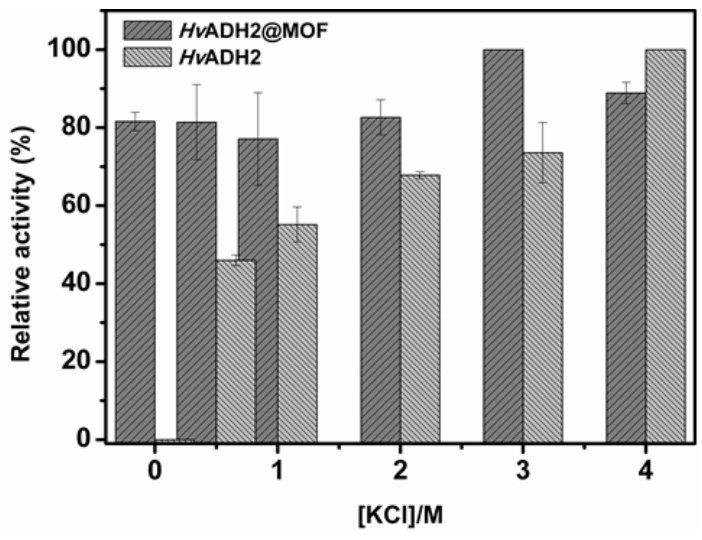

Figure 5. Relative activity of $\mathrm{HvADH} 2$ after $1 \mathrm{~h}$ incubation at $25{ }^{\circ} \mathrm{C}$ in buffer $(0.1 \mathrm{M}$ Tris, $\mathrm{pH} 10)$ at various concentrations of $\mathrm{KCl}$. The activity was normalized at buffer Tris $\mathrm{pH}=10 \mathrm{KCl} 3 \mathrm{M}$ for $\mathrm{HvADH} 2(0.02 \pm 0.01 \mathrm{U} / \mathrm{mg})$ and for HvADH2 @ MOF $(0.48 \pm 0.16$ $\mathrm{U} / \mathrm{mg}$ ) at enzyme concentration.

It is likely that the MOF provides a stable environment for the enzyme, allowing it to retain activity even at lower salt concentration $(<3 \mathrm{M})$. To ensure a homogeneous diffusion of $\mathrm{KCl}$ within the material HvADH2@MOF was also assayed after incubation of $24 \mathrm{~h}$ in $100 \mathrm{mM}$ Tris- $\mathrm{HCl}$ buffer in a wide range of $\mathrm{KCl}$ concentration to ensure a homogeneous diffusion of $\mathrm{KCl}$ within the material (Figure 5). On incubating HvADH2@MOF and HvADH in $0 \mathrm{M} \mathrm{KCl}$ after $24 \mathrm{~h}$ no activity was observed in both cases (Figure 6) in agreement with previous immobilization of $\mathrm{HvADH} 2$ on polymeric beads. ${ }^{11}$ However, despite previous immobilization strategy on $\mathrm{HvADH} 2$, good retention of activity of HvADH2@MOF (>60\%) was observed after incubation in $1.5 \mathrm{M} \mathrm{KCl}$, while the free HVADH2 only show $20 \%$ of its activity under the same conditions. A decrease in halophilicity due to the immobilization has been reported by D'Souza on Haloferax mediterranei aldolase ${ }^{56}$ and by Koch-Schmidt on the Halobacterium malate dehydrogenase. ${ }^{57}$ They found a shift in the ionic strength comparing the free malate dehydrogenase and the immobilized one in Sepharose $\mathrm{Cl} 4 \mathrm{~B}$. The free enzyme showed no activity at $0 \mathrm{M} \mathrm{KCl}$ while when the same enzyme was immobilized $80 \%$ of relative activity was observed. In our study the decrease of $\mathrm{KCl}$ requirements may be due to electrostatic interactions between the enzyme (with an excess of negative charge due to the high content of acidic aminoacids) and the ionic nature of the MOF, which may act as a substituent for the stabilizing 
$\mathrm{K}^{+}$providing a good ion-pair microenviroment for the enzyme. In-situ immobilization in MOF enables good retention of activity at lower salt concentrations that may have applications at lower salt concentrations.

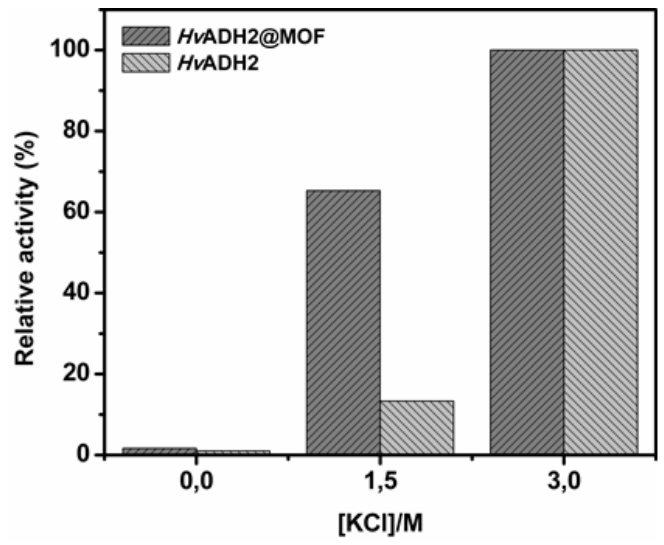

Figure 6. Relative activity of $\mathrm{HvADH} 2$ (free and immobilised) after $24 \mathrm{~h}$ incubation at $5{ }^{\circ} \mathrm{C}$ in $(0.1 \mathrm{M}$ Tris, $\mathrm{pH} 10)$ at various concentrations of $\mathrm{KCl}$.

\subsection{Stability}

Samples of HvADH2@MOF were kept in the fridge at $5^{\circ} \mathrm{C} . \mathrm{HvADH}$ @@MOF retained 20\% activity after at least one week. ScADH@MOF (ADH from Saccharomyces cerevisiae) was more stable, with $60 \%$ activity retained after 18 days. ${ }^{41}$

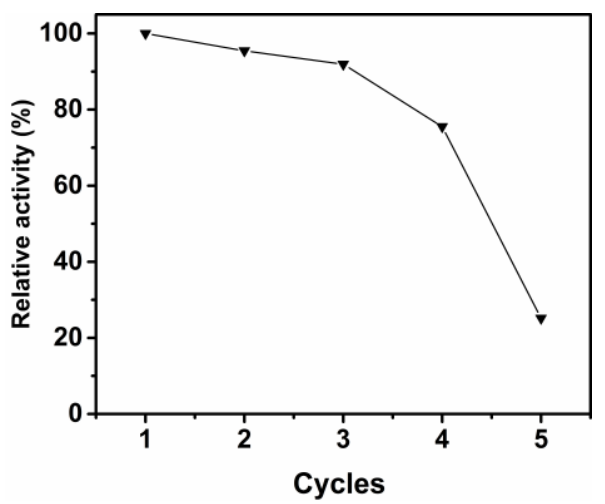

Figure 7. Plot of the activity of HvADH2@MOFas function of number of reaction cycles

One of the main advantages of enzyme immobilization is the ability to recover and reuse the biocatalyst. As shown in Figure 7 the enzyme retained up to $75 \%$ of its activity up to 4 cycles losing the most of its activity after 5 cycles (retention of $20 \%$ ). With ScADH@MOF the activity remained stable (100\%) for the first two cycles and then decreased to 55\% between the third and fifth cycles. As other MOF immobilized enzymes (glucose oxidase and lipase) retained activity for a number of cycles, the loss in activity for the alcohol dehydrogenases is possibly due to a decrease in the stability of the enzyme on re-use. Furthermore, no leaching and no enzyme activity was detected after each reuse, indicating the immobilized enzyme is stable and catalytically active.

\subsection{Stability in organic media}



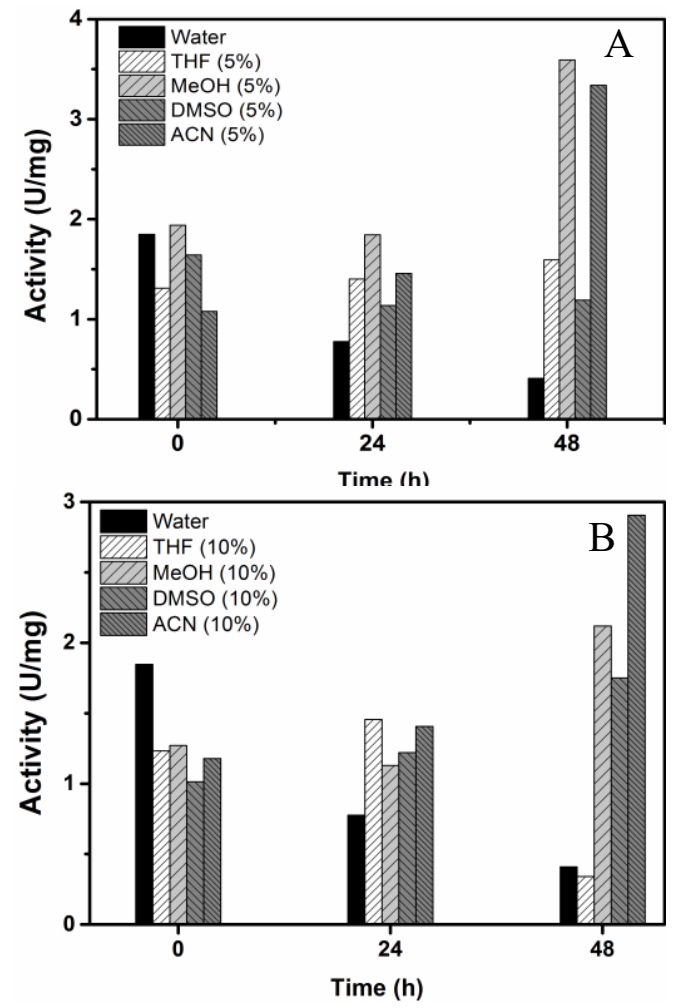

Figure 8. Activity profiles of HvADH2@MOF after storage in the presence of a range of organic media 5\% (A) and 10\% (B). The immobilised enzymes were maintained at $25^{\circ} \mathrm{C}$ and tested after 0,24 and 48 hours.

Fundamental developments in enzyme engineering and supports allow the introduction of organic media in biocatalysis. Since halophilic enzymes are active in high salt concentrations with reduced activity in pure water solutions, they are extremely valuable for their use in organic solvents. Many extremoenzymes show improved activity in organic solvents when immobilised. ${ }^{58}$ Previous studies on the effect of organic solvents on the activity of HvADH2 demonstrated that the stability of the enzyme, strongly influenced by $\mathrm{KCl}$ concentration, was improved on the addition of $\mathrm{MeOH}$ and DMSO. In this study the immobilization of HvADH2 in MOF material enhanced the activity in non-aqueous solvent mixtures (5\% and 10\%) (Figure 8). The activity of HvADH2@MOF was highest in solutions of $\mathrm{MeOH}$ and $\mathrm{ACN}$. The activity decreased over time in the absence of nonaqueous solvents, but increased by $50 \%$ in the presence of $5 \%$ THF and $\mathrm{MeOH}$. The same trend was observed with $\mathrm{MeOH}(10 \%)$ with a smaller increase in activity $(43 \%)$ while in the presence of THF the activity drops. No clear trend in terms of relating enzymatic activity with properties such as solvent polarity was observed. In contrast the activity of ADH (H. mediterranei $)^{59}$ increased with increasing solvent polarity. Similar to the results described here, Alsafadi et al. ${ }^{1}$ reported that the requirement for high concentrations of $\mathrm{KCl}$ was reduced on addition of $\mathrm{MeOH}$ and DMSO.

\section{Conclusions}

This work has focused on the immobilization of a hyperhalophilic alcohol dehydrogenase in a MOF material. The only report to date on the immobilization of the enzyme has been by covalent attachment. ${ }^{11}$ The process used to immobilize enzymes in Fe-BTC MOF materials ${ }^{41}$ can be extended to a broad range of enzymes improving their properties. The interactions between the material and the enzyme provide a favorable microenvironment broadening the operational conditions. Encapsulation of the enzyme resulted in an increase of optimal work temperature (from $50{ }^{\circ} \mathrm{C}$ to $60{ }^{\circ} \mathrm{C}$ ), a broader range of working $\mathrm{pH}$, a decrease in the requirement for high concentrations of salt, good storage stability and retention of activity in organic media such as DMSO and ACN that is not achievable with the free enzyme.

\section{ASSOCIATED CONTENT}

Supporting Information, this material is available free of charge via the Internet at http://pubs.acs.org.

\section{AUTHOR INFORMATION}

\section{Corresponding Author}

*Edmond Magner

Edmond.magner@ul.ie

\section{Author Contributions}


The manuscript was written through contributions of all authors.

\section{ACKNOWLEDGMENT}

This work has emanated from research conducted with the financial support of the Synthesis and Solid State Pharmaceutical Centre (SSPC), funded by Science Foundation Ireland (SFI) under grant 12/RC/2275. Support from the Programme for Third Level Institutions, the Irish Research Council (postdoctoral fellowship to V.G. GOIPD/2015/287) is gratefully acknowledged.

\section{ABBREVIATIONS}

ADH, alcohol dehydrogenase; MOF, metal organic framework; HvADH2, alcohol dehydrogenase from Haloferax volcanii; ScADH, alcohol dehydrogenase from Saccharomyces cerevisiae; MeOH, methanol, THF, tetrahydrofuran; DMSO, Dimethyl sulfoxide; ACN, acetonitrile.

\section{REFERENCES}

(1) Alsafadi, D.; Paradisi, F., Effect of organic solvents on the activity and stability of halophilic alcohol dehydrogenase (ADH2) from Haloferax volcanii. Extremophiles 2013, 17 (1), 115-122.

(2) Sinha, R.; Khare, S. K., Effect of organic solvents on the structure and activity of moderately halophilic Bacillus sp. EMB9 protease. Extremophiles 2014, 18 (6), 1057-1066.

(3) Oren, A., Microbial life at high salt concentrations: phylogenetic and metabolic diversity. Saline Systems 2008, 4 (1), 2.

(4) Panke, S.; Wubbolts, M., Advances in biocatalytic synthesis of pharmaceutical intermediates. Curr. Opin. Chem. Biol. 2005, 9 (2), 188-194.

(5) Patel, R. N., Biocatalytic Synthesis of Chiral Pharmaceutical Intermediates. Food Techonol. Biotechnol. 2004, 42 (4), $305-325$.

(6) Secundo, F., Conformational changes of enzymes upon immobilisation. Chem. Soc. Rev. 2013, 42 (15), 6250-6261.

(7) Danson, M. J.; Hough, D. W., The Structural Basis of Protein Halophilicity. Comp. Biochem. Physiol., Part A Mol. Integr. Physiol. 1997, 117 (3), 307-312.

(8) Timpson, L. M.; Liliensiek, A.-K.; Alsafadi, D.; Cassidy, J.; Sharkey, M. A.; Liddell, S.; Allers, T.; Paradisi, F., A comparison of two novel alcohol dehydrogenase enzymes (ADH1 and ADH2) from the extreme halophile Haloferax volcanii. Appl Microbiol Biotechnol 2013, 97 (1), 195-203.

(9) Dhakar, K.; Pandey, A., Wide pH range tolerance in extremophiles: towards understanding an important phenomenon for future biotechnology. Appl. Microbiol. and Biotechnol. 2016, 100 (6), 2499-2510.

(10) Sinha, R.; Khare, S. K., Protective role of salt in catalysis and maintaining structure of halophilic proteins against denaturation. Front. Microbiol. 2014, 5 (165).

(11) Alsafadi, D.; Paradisi, F., Covalent Immobilization of Alcohol Dehydrogenase (ADH2) from Haloferax volcanii: How to Maximize Activity and Optimize Performance of Halophilic Enzymes. Mol. Biotechnol. 2014, 56 (3), 240-247.

(12) Homaei, A. A.; Sariri, R.; Vianello, F.; Stevanato, R., Enzyme immobilization: an update. J. Chem. Biol. 2013, 6 (4), $185-205$.

(13) Guisán, J., Aldehyde-agarose gels as activated supports for immobilization-stabilization of enzymes. Enzyme Microb. Technol. 1988, $10(6), 375-382$.

(14) Mateo, C.; Abian, O.; Fernández-Lorente, G.; Pedroche, J.; Fernández-Lafuente, R.; Guisan, J. M., Epoxy Sepabeads: A Novel Epoxy Support for Stabilization of Industrial Enzymes via Very Intense Multipoint Covalent Attachment. Biotechnol. Progr. 2002, 18 (3), 629-634.

(15) Diaz, J. F.; Balkus, K. J., Enzyme immobilization in MCM-41 molecular sieve. J. Mol. Catal. B: Enzym. 1996, 2 (2-3), 115-126.

(16) Yiu, H. H. P.; Wright, P. A.; Botting, N. P., Enzyme immobilisation using SBA-15 mesoporous molecular sieves with functionalised surfaces. J. Mol. Catal. B: Enzym. 2001, 15 (1-3), 81-92.

(17) Magner, E., Immobilisation of enzymes on mesoporous silicate materials. Chem. Soc. Rev. 2013, 42 (15), $6213-6222$.

(18) Salis, A.; Meloni, D.; Ligas, S.; Casula, M. F.; Monduzzi, M.; Solinas, V.; Dumitriu, E., Physical and Chemical Adsorption of Mucor javanicus Lipase on SBA-15 Mesoporous Silica. Synthesis, Structural Characterization, and Activity Performance. Langmuir 2005, 21 (12), 5511-5516.

(19) Mehta, J.; Bhardwaj, N.; Bhardwaj, S. K.; Kim, K.-H.; Deep, A., Recent advances in enzyme immobilization techniques: Metal-organic frameworks as novel substrates. Coord. Chem. Rev. 2016, 322, 30-40.

(20) Lian, X.; Fang, Y.; Joseph, E.; Wang, Q.; Li, J.; Banerjee, S.; Lollar, C.; Wang, X.; Zhou, H.-C., Enzyme-MOF (metal-organic framework) composites. Chem. Soc. Rev. 2017, 46 (11), 3386-3401.

(21) Lykourinou, V.; Chen, Y.; Wang, X.-S.; Meng, L.; Hoang, T.; Ming, L.-J.; Musselman, R. L.; Ma, S., Immobilization of MP-11 into a Mesoporous Metal-Organic Framework, MP-11@mesoMOF: A New Platform for Enzymatic Catalysis. J. Am. Chem. Soc. 2011, 133 (27), 10382-10385.

(22) E. Castro Miguel; V. Gascon; M. Diaz Garcia, R. B. M. S.-S. 2016.

(23) Furukawa, H.; Gándara, F.; Zhang, Y.-B.; Jiang, J.; Queen, W. L.; Hudson, M. R.; Yaghi, O. M., Water Adsorption in Porous MetalOrganic Frameworks and Related Materials. J. Am. Chem. Soc. 2014, 136 (11), 4369-4381.

(24) Li, B.; Wen, H.-M.; Zhou, W.; Chen, B., Porous Metal-Organic Frameworks for Gas Storage and Separation: What, How, and Why? J. Phys. Chem. Lett. 2014, 5 (20), 3468-3479.

(25) Li, J.-R.; Sculley, J.; Zhou, H.-C., Metal-Organic Frameworks for Separations. Chem. Rev. 2012, 112 (2), $869-932$.

(26) Kumar, P.; Deep, A.; Kim, K.-H., Metal organic frameworks for sensing applications. Trends Analyt. Chem. 2015, 73, $39-53$.

(27) Zhang, Y.; Ying, J. Y., Main-Chain Organic Frameworks with Advanced Catalytic Functionalities. ACS Catalysis 2015, 5 (4), 26812691.

(28) Horcajada, P.; Surble, S.; Serre, C.; Hong, D.-Y.; Seo, Y.-K.; Chang, J.-S.; Greneche, J.-M.; Margiolaki, I.; Ferey, G., Synthesis and catalytic properties of MIL-100(Fe), an iron(iii) carboxylate with large pores. ChemComm. 2007, (27), $2820-2822$. 
(29) Jiang, H.-L.; Xu, Q., Porous metal-organic frameworks as platforms for functional applications. Chem. Comm. 2011, 47 (12), 3351 3370.

(30) Gascon, V.; Castro-Miguel, E.; Diaz-Garcia, M.; Blanco, R. M.; Sanchez-Sanchez, M., In situ and post-synthesis immobilization of enzymes on nanocrystalline MOF platforms to yield active biocatalysts. J. Chem. Technol. Biotechnol. 2017, 92 (10), $2583-2593$.

(31) Stock, N.; Biswas, S., Synthesis of Metal-Organic Frameworks (MOFs): Routes to Various MOF Topologies, Morphologies, and Composites. Chem. Rev. 2012, 112 (2), 933-969.

(32) Deng, H.; Grunder, S.; Cordova, K. E.; Valente, C.; Furukawa, H.; Hmadeh, M.; Gándara, F.; Whalley, A. C.; Liu, Z.; Asahina, S.; Kazumori, H.; O'Keeffe, M.; Terasaki, O.; Stoddart, J. F.; Yaghi, O. M., Large-Pore Apertures in a Series of Metal-Organic Frameworks. Science 2012, 336 (6084), 1018-1023.

(33) Lyu, F.; Zhang, Y.; Zare, R. N.; Ge, J.; Liu, Z., One-Pot Synthesis of Protein-Embedded Metal-Organic Frameworks with Enhanced Biological Activities. Nano Lett. 2014, 14 (10), 5761-5765.

(34) Balkus, K. J.; Pisklak, T. J.; Huang, R., Microperoxidase-11 Immobilized in a Metal Organic Framework. In Biomolecular Catalysis, American Chemical Society: 2008; Vol. 986, pp 76-98.

(35) Urrego, S.; Serra, E.; Alfredsson, V.; Blanco, R. M.; Díaz, I., Bottle-around-the-ship: A method to encapsulate enzymes in ordered mesoporous materials. Microporous Mesoporous Mater. 2010, 129 (1), 173-178.

(36) Gascon, V. M.-Á., Carlos; Blanco, Rosa Maria Successful encapsulation of $\beta$-glucosidase during the synthesis of siliceous mesostructured materials. J. Chem. Technol. Biotechnol. 2018.

(37) Wu, X.; Ge, J.; Yang, C.; Hou, M.; Liu, Z., Facile synthesis of multiple enzyme-containing metal-organic frameworks in a biomoleculefriendly environment. Chem Comm 2015, 51 (69), 13408-13411.

(38) Liang, K.; Coghlan, C. J.; Bell, S. G.; Doonan, C.; Falcaro, P., Enzyme encapsulation in zeolitic imidazolate frameworks: a comparison between controlled co-precipitation and biomimetic mineralisation. Chem. Comm. 2016, 52 (3), 473-476.

(39) Gkaniatsou, E.; Sicard, C.; Ricoux, R.; Mahy, J.-P.; Steunou, N.; Serre, C., Metal-organic frameworks: a novel host platform for enzymatic catalysis and detection. Mater. Horizons 2017, 4 (1), 55-63.

(40) Federica, P.; Cristina, C.; Maryam, N.; Lida, F.; Edmond, M.; Andrea, S., Lipase Encapsulation onto ZIF-8: A Comparison between Biocatalysts Obtained at Low and High Zinc/2-Methylimidazole Molar Ratio in Aqueous Medium. ChemCatChem 2018, 10 (7), 15781585.

(41) Gascón, V.; Carucci, C.; Jiménez, M. B.; Blanco, R. M.; Sánchez-Sánchez, M.; Magner, E., Rapid In Situ Immobilization of Enzymes in Metal-Organic Framework Supports under Mild Conditions. ChemCatChem 2017, 9 (7), 1182-1186.

(42) Dhakshinamoorthy, A.; Alvaro, M.; Horcajada, P.; Gibson, E.; Vishnuvarthan, M.; Vimont, A.; Grenèche, J.-M.; Serre, C.; Daturi, M.; Garcia, H., Comparison of Porous Iron Trimesates Basolite F300 and MIL-100(Fe) As Heterogeneous Catalysts for Lewis Acid and Oxidation Reactions: Roles of Structural Defects and Stability. ACS Catalysis 2012, 2 (10), 2060-2065.

(43) Sanchez-Sanchez, M.; de Asua, I.; Ruano, D.; Diaz, K., Direct Synthesis, Structural Features, and Enhanced Catalytic Activity of the Basolite F300-like Semiamorphous Fe-BTC Framework. Cryst. Growth Des. 2015, 15 (9), 4498-4506.

(44) Sanchez-Sanchez, M.; Getachew, N.; Diaz, K.; Diaz-Garcia, M.; Chebude, Y.; Diaz, I., Synthesis of metal-organic frameworks in water at room temperature: salts as linker sources. Green Chem. 2015, 17 (3), 1500-1509.

(45) Sapan, C. V.; Lundblad, R. L.; Price, N. C., Colorimetric protein assay techniques. Biotechnol. and Appl. Biochem. 1999, 29 (2), $99-$ 108.

(46) Kägi, J. H. R.; Vallee, B. L., The Role of Zinc in Alcohol Dehydrogenase: V. THE EFFECT OF METAL-BINDING AGENTS ON THE STRUCTURE OF THE YEAST ALCOHOL DEHYDROGENASE MOLECULE. J. Biol. Chem. 1960, 235 (11), $3188-3192$.

(47) Gascon, V.; Jimenez, M. B.; Blanco, R. M.; Sanchez-Sanchez, M., Semi-crystalline Fe-BTC MOF material as an efficient support for enzyme immobilization. Catal. Today 2018, 304, 119-126.

(48) Lanyi, J. K., Salt-dependent properties of proteins from extremely halophilic bacteria. Bacteriol. Rev. 1974, 38 (3), $272-290$.

(49) Sinha, R.; Khare, S. K., Protective role of salt in catalysis and maintaining structure of halophilic proteins against denaturation. Front. Microbiol. 2014, 5, 165.

(50) Cassidy, J.; Bruen, L.; Rosini, E.; Molla, G.; Pollegioni, L.; Paradisi, F., Engineering substrate promiscuity in halophilic alcohol dehydrogenase (HvADH2) by in silico design. PLoS One 2017, 12 (11), 11.

(51) Nadar, S. S.; Rathod, V. K., Facile synthesis of glucoamylase embedded metal-organic frameworks (glucoamylase-MOF) with enhanced stability. Int J Biol Macromol 2017, 95, 511-519.

(52) Mevarech, M.; Frolow, F.; Gloss, L. M., Halophilic enzymes: proteins with a grain of salt. Biophys. Chem. 2000, 86 (2), $155-164$.

(53) Oren, A., Industrial and environmental applications of halophilic microorganisms. Environ. Technol. 2010, 31 (8-9), 825-834.

(54) Danson, M. J.; Hough, D. W., The Structural Basis of Protein Halophilicity. Comp. Biochem. Physiol. A Physiol. 1997, 117 (3), $307-$ 312.

(55) Allers, T.; Barak, S.; Liddell, S.; Wardell, K.; Mevarech, M., Improved Strains and Plasmid Vectors for Conditional Overexpression of His-Tagged Proteins in Haloferax volcanii. Appl Environ Microbiol 2010, 76 (6), 1759-1769.

(56) D'Souza, S. E.; Altekar, W.; D'Souza, S. F., Immobilization of Haloferax mediterranei aldolase by cross-linking in a proteinic matrix: stability and halophilic characteristics. World J. Microb. and Biotechnol. 1997, 13 (5), 561-564.

(57) Koch-Schmidt, A. C.; Mosbach, K.; Werber, M. M., A Comparative Study on the Stability of Immobilized Halophilic and NonHalophilic Malate Dehydrogenases at Various Ionic Strengths. Eur. J. Biochem. 1979, 100 (1), 213-218.

(58) Sellek, G. A.; Chaudhuri, J. B., Biocatalysis in organic media using enzymes from extremophiles. Enzyme and Microb. Technol. 1999, $25(6), 471-482$.

(59) D'Souza, S. E.; Altekar, W.; D'Souza, S. F., Immobilization of Haloferax mediterranei aldolase by cross-linking in a proteinic matrix: stability and halophilic characteristics. World Journal of Microbiology and Biotechnology 1997, 13 (5), 561-564. 